\title{
Measuring emissions avoided by international trade: accounting for price differences
}

\author{
Iñaki Artoa,b,*, Jordi Rocac and Mònica Serranod
}

a European Commission, Joint Research Centre, Institute for Prospective an Technological Studies. Edificio EXPO, C/Inca Garcilaso 3; 41092 Sevilla, Spain. inaki.arto@ec.europa.eu

b EKOPOL, Research Group on Ecological Economics \& Political Ecology, University of the Basque Country, Spain. i.arto@ehu.es

c Department of Economic Theory, University of Barcelona, Faculty of Economic and Business. Avda. Diagonal 696, 08034 Barcelona, Spain. jordiroca@ub.edu

d Department of Economic Theory, University of Barcelona, Faculty of Economic and Business. Avda. Diagonal 696, 08034 Barcelona, Spain. monica.serrano@ub.edu

* Corresponding author. Tel: + 34954488 376; Fax: + 34954488235

\section{Abstract:}

Net Emissions Avoided by trade (NEA) are the difference between the pollution that would have been produced in a country if it had not exported any product and all necessary imports to satisfy its domestic demand had been produced internally and its actual emissions. The Domestic Technology Assumption (DTA) applied to an Environmental Extended Input-Output model is the appropriate method to estimate the NEA. In practice, the implementation of the DTA involves that the country analyzed should produce a quantity of products equivalent to the monetary value of the imports required to satisfy its final demand (i.e. 'monetary DTA'). However, due to price differences, it could be the case that the same physical quantity of goods in different countries would have a different monetary value. In that case, monetary imports should be adapted to reflect the physical quantity of goods imported. In this paper we show that a 'physical DTA', focused on the pollution to produce domestically the imports measured in physical units, would be a better approach. We have applied both methodologies to analyze greenhouse gas emissions in Spain 1995-2007. Both methodologies show that Spain is avoiding emissions through trade (i.e. NEA are positive). However, the emissions avoided by trade increase up to three times when applying the 'physical DTA', showing that results from the 'monetary DTA' are biased by price differences.

\section{Keywords:}


Emissions avoided; International trade; Environmental Extended Input-Output Analysis; Domestic Technology Assumption; Price differences; Greenhouse gas emissions.

J.E.L. classification codes: C67, F18, Q53.

\section{Acknowledgments and disclaimer:}

Earlier versions of this paper were presented with the title of "Accounting for embodied emissions in international trade: physical vs monetary trade flows" at the Summer School on Environmental accounting externality valuation and Input-Output tools for policy analysis, 11-17 July 2010, Venice, Italy; and at the IV Spanish Conference on Input-Output Analysis, 28-30 September 2011, Madrid, Spain. Also at the International Society for Ecological Economics Conference, 22 - 25 August 2010, Oldenburg \& Bremen, Germany with the tittle "The countries' responsibility for greenhouse emissions: the role of trade. An application to Spain". We are grateful to the participants in these conferences for their comments. Our gratitude is also extended to five anonymous referees for their remarks, especially to Erik Dietzenbacher for his very valuable review. Jordi Roca and Mònica Serrano gratefully acknowledge financial support from the projects ECO2009-11099 (Ministerio de Ciencia e Innovación), ECO2012-34591, HAR2012-38920-C02-02 (Ministerio de Economía y Competitividad), and 2009SGR-517 (Generalitat de Catalunya).

Disclaimer: The views expressed in this paper are those of the authors and should not be attributed to the European Commission or its services. 


\section{Introduction}

In recent years, there has been an increasing interest in assessing the environmental consequences of international trade and their policy implications. One of the most relevant questions is the extent to which countries are taking advantage (or being damaged) from trade by displacing regional or local pollution to other regions. By importing goods and services, one country could benefit from the consumption of such commodities and, at the same time, by avoiding the emissions generated away when producing those goods. On the contrary, exporting countries would support the environmental costs of producing those goods. This situation has been called 'environmental load displacement' or 'environmental cost shifting' (Muradian and Martínez-Alier, 2001) and it is closely connected to some controversial hypotheses such as the 'Environmental Kuznets Curve' (Grossman and Krueger, 1991; Arrow et al., 1995; Stern et al., 1996; Roca, 2003) or the 'pollution haven hypothesis' (Dietzenbacher and Mukhopadhyay, 2007).

The interest on trade and environmental pressures has also been especially strong in the field of climate change (Weidema et al., 2006; Peters and Hertwich, 2008; Serrano and Dietzenbacher, 2010; Peters et al., 2011). In this case two outstanding debates rotate around the 'carbon leakage' (Wyckoff and Roop, 1994) and how to share the responsibility for greenhouse gases (GHG) emissions between producing and consuming countries (Gallego and Lenzen, 2005; Lenzen et al., 2007; Peters, 2008).

In this context, the estimation of the effects of trade in domestic emissions has a significant role and it becomes an important element to determine which countries are being environmentally benefitted (or harmed) from trade. This issue may be analyzed from two different approaches: by calculating the emissions avoided by trade or by computing the 'emission trade balance' (ETB). Although both concepts look very similar and, in some cases, they have been used in the literature indistinctly, they are conceptually distinct and, in fact, they answer different research questions as discussed later.

Undoubtedly, if one wants to assess what would have been the domestic emissions of a country if there were not international trade (neither exports nor imports) 
and all the domestic demand had been completely provided by domestic production, 1 the appropriate approach is to calculate the Net Emission Avoided by trade (NEA). By definition, NEA is the difference between the emissions that would take place in that country if it was closed to international trade (Emissions Without Trade, EWoT) and its actual emissions. If the NEA is positive, trade would be "beneficial" for the country by contributing to reduce the domestic emissions; otherwise, trade would be "harmful". In the case of global pollutants, such as GHG, it would be "beneficial" (or "harmful") in the sense that the country would appear as less (more) polluting, while in the case of local/regional pollution the benefits (or costs) would affect the environmental quality in the country really.

The estimation of EWoT implies applying the so-called Domestic Technology Assumption (DTA) in the framework of an Environmentally Extend Input-Output (EEIO) model. Although we maintain the name DTA, in this case it is not really an "assumption" but an implication of the research objective. So far, the practical implementation of the DTA has involved that the country analyzed should produce domestically (i.e. with its domestic technology) 2 a quantity of products equivalent to the monetary value of the imports required to satisfy its domestic final demand (i.e. 'monetary DTA').3 However, the monetary value of goods depends on both the quantity and the price of traded goods. Consequently, due to price differences among countries, it could be the case that the same physical quantity of goods in different countries would have a different monetary value. In such a case, applying the 'monetary DTA' to estimate the emissions derived of producing imported goods using the domestic technology would result in different volumes of emissions for the same physical quantity of domestic and imported goods.

In order to overcome this shortcoming, in this paper we propose a new approach for calculating the EWoT and, consequently, the NEA based on the idea that the emissions avoided by imports should reflect the pollution to produce domestically the

1 This is a hypothetical assumption that implies that any good imported could be produced domestically. In fact, there are imported goods which would be impossible produce domestically due to the absence of some inputs. This is the case, for instance, of crude oil for countries that have not this natural resource. 2 From the perspective of an EE-IO model the technology of each sector is defined by its emission intensity and its input structure.

3 Examples of the use of this method can be found in Ackerman et al. (2007), Dietzenbacher and Mukhopadhyay (2007), Peters et al. (2007), Lin and Sun (2010), Liu et al. (2010); Rueda-Cantuche (2011) or Zhang (2012). 
same quantity of imported goods but measured in physical terms. That is what we call the 'physical DTA'.

In this paper the 'physical DTA' is applied to the analysis of the NEA of GHG in Spain for the period 1995-2007 and we compare the results with those obtained from the standard 'monetary DTA'.

Although it is not the main focus of this paper, we consider necessary to revisit the issue of the conceptual difference between the NEA and ETB we discussed at the beginning of this section. 4 Both the NEA and ETB assess the effects of trade in domestic emissions, but the focus is different. Whereas the NEA allows estimating to what extent countries are taking advantage from trade by avoiding pollution in its territory, the ETB allows assessing the difference between the emissions embodied in the imports and in the exports. 56

As it has been extensively argued in the literature, the proper way to estimate emissions embodied in trade and ETB is to apply Environmentally Extended Multiregional Input-Output (EE-MRIO) models. However, until the publication of MRIO databases such as GTAP, EXIOPOL, WIOD or EORA, many studies applied the DTA (Wiedmann, et al., 2007; Wiedmann, 2009; Rueda-Cantuche, 2011; Dietzenbacher and Tukker, 2013). Consequently, the quantitative results of both concepts -the NEA and the ETB- were the same and this would be the reason why on some occasions both concepts could have been used interchangeably in the literature creating some confusion. Nevertheless, the proliferation of MRIO databases allows omitting the use of the DTA for calculating ETB. Then, the estimation of ETB and -in consequence- emissions from the 'consumer responsibility' perspective (i.e. carbon footprint) applying the DTA will be justified only in specific cases. For instance, when the analysis refers to a country or a region without individual data in MRIO databases or when the high level of disaggregation of national Input-Output (IO) tables justifies adopting this approach. In this sense, the methodological innovation for estimating the NEA presented in this paper would also be relevant when for any reason it was applied the DTA to estimate

\footnotetext{
4 The difference between NAE and ETB is also relevant for the political debate on "carbon border tax adjustments" (see Mattoo et al. 2009).

5 The ETB can also be obtained by the difference between emissions from the 'consumer' and 'producer' responsibilities. For a detail discussion see Serrano and Dietzenbacher (2010).

6 The NEA and ETB are not equal due to differences in technologies of countries. Imagine a country with positive NEA, as it is the case for the most part of rich countries. If this country imports commodities
} 
emissions from the 'consumer responsibility' perspective. In fact, in previous studies we applied the 'physical DTA' to estimate carbon footprints and ETB in Spain (Arto, 2009; Arto et al., 2010a,b; 2012).7

The structure of the paper is as follows. After this introduction, section 2 explains in detail the methodology for calculating the NEA according to the 'monetary DTA' and to the 'physical DTA'. Section 3 describes the database used in the case study and reports the results. Finally, section 4 presents the conclusions.

\section{Methodology}

\subsection{Formalization of the 'monetary-DTA' and 'physical-DTA'}

The starting point of our analysis is the IO table of a country as shown in Figure 1. This figure describes the flows of goods and services between all the sectors and the use by final users: $\mathbf{Z}^{\mathbf{D}}$ is the matrix of intermediate deliveries, $\mathbf{f}^{\mathbf{D}}$ is the column vector of final demand for domestic commodities, $\mathbf{e}$ is the column vector of total exports, $\mathbf{x}$ is the column vector of total output, $\mathbf{Z}^{\mathbf{M}}$ is the matrix of imported intermediate commodities, $\mathbf{f}^{\mathbf{M}}$ is the column vector of final demand for imported commodities, $\mathbf{x}^{\mathbf{M}}$ is the vector of total imports, and $\mathbf{w}^{\prime}$ is the transpose of the vector of sectoral value added. Figure 1 has been extended with the transpose of the vector of sectoral emissions ( $\left.\mathbf{g}^{\prime}\right)$. Matrices of input coefficients for domestic and imported intermediate commodities are given by $\mathbf{A}^{\mathbf{D}}=\mathbf{Z}^{\mathrm{D}} \hat{\mathbf{x}}^{-1}$ and $\mathbf{A}^{\mathbf{M}}=\mathbf{Z}^{\mathbf{M}} \hat{\mathbf{x}}^{-1}$, where $\hat{\mathbf{x}}^{-1}$ denotes the inverse of the diagonal matrix of the vector of total output.

\section{Figure 1}

We are interested on assessing to what extent trade contributes to reduce (or to increase) the emissions in the country analyzed; this is equivalent to estimating the NEA. The NEA is the difference between two elements: $i$ ) EWoT: the emissions that would have been generated if the country had not exported any commodity and all necessary

from other countries, whose average technologies were more polluting than its own technology, then the ETB would be higher than the NEA; in the opposite case it would be lower.

7 Later, Tukker et al. (2013) applied a similar approach to study the emission trade balance for the European Union. 
imports to satisfy its domestic final demand had been produced in the country using its own technology; and ii) the emissions actually released by the country.

Now, the question is how to measure EWoT, which includes the emissions provoked by producing the amount of imports that the country should substitute to satisfy with domestic production the domestic final demand (denoted by $\mathbf{f}=\mathbf{f}^{\mathrm{D}}+\mathbf{f}^{\mathbf{M}}$ ) and excludes all the emissions linked to the production of exported products $(\mathbf{e})$. The EWoT can be calculated as the sum of the emission generated in the different steps of the supply chain. These emissions would include the direct emissions to produce domestically $\mathbf{f}$, the emissions generated when producing the domestic inputs to produced $\mathbf{f}$, the emissions generated to produced domestically the imported inputs (measured in monetary terms) to produce $\mathbf{f}$, and so on. Formally, these emissions calculated following the 'monetary DTA' would read as

$$
\mathrm{EWoT}=\mathbf{c}^{\prime}(\mathbf{I}-\mathbf{A})^{-1} \mathbf{f}
$$

where $\mathbf{c}^{\prime}$ is the transpose of vector of emission coefficients, and the term $(\mathbf{I}-\mathbf{A})^{-1}$ is the Leontief inverse using the total coefficients matrix $A$, with $A=A^{D}+A^{M}$.

Then, NEA results from comparing EWoT according to equation [1] and vector $\mathbf{g}$ reads as follows

$$
\mathrm{NAE}=\mathrm{EWoT}-\mathbf{g}^{\prime} \mathbf{i}
$$

where $\mathbf{i}$ is a column vector of 1 of appropriate dimension.

If $\mathrm{NAE}>0$ the country would have taken advantage from trade, in the sense that its emissions would have been higher in the case it had satisfied all its domestic demand with domestic production without imports or exports.

However, the estimation of EWoT according to the 'monetary DTA' applied to the estimation of EWoT in equation [1] would report different levels of emissions for the same physical quantity of imported and domestic produced goods. As pointed before, the monetary value of goods depends on both the quantity and the price of traded goods. Consequently, due to price differences among countries, it could be the case that the same physical quantity of goods in different countries would have a different monetary value. In such a case, applying the 'monetary DTA' to the estimation of the emissions to produce domestically imported goods would result in different 
volumes of emissions for the same physical quantity of domestic and imported goods. In order to overcome this limitation we propose to assess EWoT taking that price difference into account, this is what we have called 'physical-DTA'.

Thus, in order to calculate the emissions according to the 'physical DTA', we have to adapt the monetary imports in the IO tables so that they reflect the physical quantity of goods imported.8 This can be done by revaluating the imports by the differential price between domestic and imported goods, which yields a different matrix of import coefficients and a different vector of final demand for imported commodities.9

Let the vector $\mathbf{p}$ give the ratio for each commodity between countries; therefore, the intermediate and final imports adjusted to reflect the differences in domestic and foreign prices would be $\overline{\mathbf{Z}}^{\mathrm{M}}=\hat{\mathbf{p}} \mathbf{Z}^{\mathrm{M}}$ and $\overline{\mathbf{f}}^{\mathbf{M}}=\hat{\mathbf{p}} \mathbf{f}^{\mathrm{M}}$. Accordingly, matrix of intermediate imports coefficients and the vector of domestic final demand would be $\overline{\mathbf{A}}^{\mathbf{M}}=\overline{\mathbf{Z}}^{\mathbf{M}} \hat{\mathbf{X}}^{-1}$ and $\overline{\mathbf{f}}^{\mathrm{I}}=\mathbf{f}^{\mathrm{D}}+\overline{\mathbf{f}}^{\mathrm{M}}$ respectively. Thus, it follows that the expressions for the EWoT calculated according to the 'physical DTA' would reads

$$
\overline{\mathrm{EWoT}}=\mathbf{c}^{\prime}(\mathbf{I}-\overline{\mathbf{A}})^{-1} \overline{\mathbf{f}}^{\prime}
$$

where $\overline{\mathbf{A}}$ represents the total coefficients matrix taking price differences of imported inputs into account (i.e. $\overline{\mathbf{A}}=\mathbf{A}^{\mathbf{D}}+\overline{\mathbf{A}}^{\mathbf{M}}$ ).

In the same way as we did for the 'monetary DTA', we can calculate the NEA to assess to what extent trade contributes to avoid emissions by comparing expression [3] and vector $\mathbf{g}$

$$
\overline{\mathrm{NEA}}=\overline{\mathrm{EWoT}}-\mathbf{g}^{\prime} \mathbf{i}
$$

In section 3 we analyze for the case of Spain 1995-2007 the EWoT and the NEA calculated as for the 'monetary DTA' (expressions 1 and 2) and applying the 'physical DTA' (expressions 3 and 4). A last remark seems in place. The analysis above is based on the assumption that each sector has only one product and the price of that product is invariable (i.e. it is the same regardless of its destination, industry or final use). In IO

8 IO tables do not usually include physical information on the flows of goods. Although there are some pilot experiences on the development of Physical Input-Output Tables, these tables are still very rare and only exist for a few countries and years (Stahmer, 2000; Strassert, 2002). 
empirical tables obviously each sector has a great number of products and this hypothesis becomes much more restrictive.

\subsection{Discussion: 'monetary-DTA' versus 'physical-DTA'}

The price of each commodity in different countries is affected by many factors such as labor costs, fiscal system and/or the existence of subsidies, trade and transport margins, etc. The exchange rates also can affect the relation between the value and the physical content of goods. The 'monetary DTA' does not take price differences into account and might result in biased estimations of the emissions avoided by trade. We can illustrate this shortcoming of the 'monetary DTA' with a very simple example. Let us assume that we wanted to calculate the net emissions avoided by a country A that is importing $\$ 100,000$ of pair of shoes from country B and exporting $\$ 200,000$ of pair of shoes. Moreover, we known that the direct and indirect emission intensity to produce shoes in country A is $0.2 \mathrm{kgCO}_{2}$ per $\$$ of shoes. Thus, the emissions embodied in export would be $\$ 200,000 \times 0.2 \mathrm{kgCO}_{2} / \$=40,000 \mathrm{kgCO}_{2}$. On the other hand, according the 'monetary DTA' we would conclude that the emissions to produce in A the imported shoes (emissions avoided) would be the result of multiplying the value of the shoes imported from B times the emission intensity in A: $\$ 100,000 \times 0.2 \mathrm{kgCO} / \$=20,000$ $\mathrm{kgCO}_{2}$. In this case, we can observe that the monetary value of exported shoes is twice the value of imports and, unsurprisingly, the emissions due to the domestic production of exported shoes are twice the emissions avoided by imports.

However, the price of exported and imported goods can be different. Coming back to the example, let us assume that the prices of shoes in country A and B are $\$ 100$ per pair of shoes and $\$ 50$ per pair of shoes respectively. It follows that the physical quantity of imported shoes by A from B would be 2,000 pairs $(\$ 100,000$ / $\$ 50$ per pair), and the physical exports of country A's shoes would be 2,000 pairs as well ( $\$ 200,000$ / $\$ 100$ per pair). Thus, country A would be importing the same physical quantity of shoes as it is exporting and obviously in the case of producing the imported shoes the emissions would also be the same: $40,000 \mathrm{kgCO}_{2}$.

\footnotetext{
9 Trade statistics offer very useful information to proceed with this deflation. Detailed trade statistics are available in terms of values and in weight which implies that price information for exports and imports can be deduced by dividing for each commodity exported and imported its value by its weight.
} 
In this simple case, due to price differences, the 'monetary DTA' would underestimate the emissions avoided by trade and the 'physical-DTA' would give the correct estimation. In other words, 'monetary-DTA' would only be a good estimation if the prices of imported and produced goods were the same. On the contrary, the 'physical DTA' take price differences into account by deflating imports and allows calculating the emissions avoided by imports according to the physical content of imported goods. In the previous example, this translates into deflating the imports (to reflect the price difference) and then multiplying by the domestic emission intensity. Therefore, from a theoretical view point, for estimating avoided emissions the 'physical DTA' would be better than the 'monetary DTA' because the former calculates embodied emissions in imports according to real quantities traded, leaving out of the analysis the effect of different prices.

Apart from price differences for the same commodities, there are also some qualitative attributes of products that can cause differences in the prices of traded goods, such as the design or the trademark (in our example, obviously the characteristics of imported and exported shoes will not be identical). These characteristics are not necessarily linked to the physical content of the commodity itself and can contribute to distort the results. This question of the qualitative attributes is related to the problem of homogeneity in IO tables. One of the assumptions underlying IO tables is that each sector consists on an aggregation of 'units of homogeneous production'. When the DTA (monetary or physical) is applied, the aggregation assumption means that each sector produces the same single product, wherever it is located. In reality, such 'units of homogeneous production' do not exist for the most part of sectors. On the empirical level, each sector could include a wide range of different products or products at different stages of processing and/or qualities, which has implications for our analysis. 10

An example of a sector with heterogeneous products is the sector of 'pulp and paper'. In order to better understand this issue, let assume the case of a country producing paper sheets and importing paper pulp, both included in 'pulp and paper' sector. Pulp is an input to produce paper sheets and emissions and value per tonne of paper sheets are higher than those of paper pulp. Here the differences would be

10 This shortcoming could be more or less important depending on the level of disaggregation, i.e. the number of different sectors considered. Wood and Dey (2009) depicts Australia's case applying the 'monetary DTA' considering 344 sectors and Levinson (2009) gives the example of US with almost 500 
determined by the relation between value added and emissions added in each stage of the value chain. Frequently, where the greater pollution is generated and the less value is added is in the earlier stages of the production process of a sector (this would be the case of paper). Consequently, in such cases, the physical weight seems to be much more relevant than the monetary value to determine the relative emissions, and probably again the 'physical DTA' would be preferable than the 'monetary DTA'. Obviously, we cannot generalize the previous example and it would be possible that in some sectors and specific cases the 'monetary DTA' might be more appropriated than the 'physical DTA'.

In conclusion, due to price differences, the 'monetary DTA' would report different levels of emissions for the same physical quantity of imported and domestic produced goods. For this reason the 'physical DTA' is clearly a better methodological option. However, a great limitation for obtaining conclusions from IO analysis is the inevitable aggregation of different products in a same sector. This is a problem for both the physical and the monetary approach and for this reason we cannot clearly prove which the best option is. But given the physical (rather than monetary) nature of generating emissions, we can conjecture that for this reason it also seems reasonable to apply a 'physical DTA' to get better results. Thus, taking all the factors into account our proposal is to carry out -whenever possible- both analyses and to give especial relevance to the outcomes from 'physical-DTA'. This is what we do in the following section for Spain.

\section{Database and Results}

\subsection{Database}

We have applied the DTA, both in monetary and physical terms, to estimate the NEA of GHG in Spain for the period 1995-2007. The main data sources are the Supply and Use Tables (SUTs) elaborated by the Spanish Statistical Institute (INE, 2010a,b), the Spanish atmospheric emissions satellite accounts (INE, 2010c), and foreign trade statistics (Agencia Tributaria, 2010). 
SUTs have been homogenized to a common classification (70 industries and 70 products) and transformed to symmetric product-by-product IO tables based on the industry technology assumption (Eurostat, 2008). The emission accounts include information of the sectoral emissions of six different GHG for 46 industries. The six GHG ( $\mathrm{CO}_{2}, \mathrm{CH}_{4}, \mathrm{~N}_{2} \mathrm{O}, \mathrm{HFCs}$, PFCs and $\left.\mathrm{SF}_{6}\right)$ have been aggregated in terms of $\mathrm{CO}_{2}$ equivalent. These emissions accounts have been transformed to pollutant-by-product accounts and have been disaggregated to match the homogeneous classification. This disaggregation has been conducted on the basis of the total output by product.

Foreign trade statistics offer annual information about flows of imports and exports, specifically: the country of origin and/or destination, the weight, and the monetary value. The information on weights, obviously, is only available for primary and industrial sectors but not for services. This information has been used to deflate according to equation [3]- the imports of intermediate and final goods of the use table for a total of 35 primary and industrial products 11 in order to apply the 'physical DTA'. Finally, we have not calculated the emissions avoided by the imports of oil and gas, since Spain does not have those resources and, therefore, it is not possible to produce them internally. Table 1 shows the deflators calculated for the whole period analyzed.

\section{Table 1}

\subsection{Results}

Figure 2 and Table 2 show the results of applying the 'monetary DTA' and the alternative 'physical DTA' proposed in this paper to calculation of the EWoT and the NEA.

Analyzing the results from both hypotheses we find that the EWoT from the 'monetary DTA' is lower than that reported by the 'physical DTA' in all the years considered, suggesting that the standard way of estimating avoided emissions by imports underestimates their quantitative importance. For the year 2007, the 'monetary DTA' estimates that without trade flows Spanish emissions would have been 472 Millions of tonnes of $\mathrm{CO}_{2}$ equivalent $\left(\mathrm{MtCO}_{2} \mathrm{e}\right)$, while according to the 'physical DTA' 
the EWoT would have reached $560 \mathrm{MtCO}_{2} \mathrm{e}$. Moreover, the gap between the results from both approaches has grown over the time. In 1995, the emissions without trade reported by the 'monetary DTA' were $4.3 \%$ lower than those from the 'physical DTA', while in 2007 , this difference increased to $15.7 \%$. This circumstance can also be seen when comparing the growth in the EWoT resulting from both approaches: $+46 \%$ for the 'monetary DTA' and $+66 \%$ for the 'physical DTA' (see Figure 2). The results also show a cumulative difference for the EWoT between both approaches of $482 \mathrm{MtCO} 2 \mathrm{e}$ for the period 1995-2007.

\section{Figure 2}

Comparing the EWoT with the actual emissions we can observe that the NEA is positive in all the years. Thus, Spain is taking advantage from trade from the perspective of climate policy, in the sense that in absence of trade Spanish emissions of GHG to satisfy the same domestic demand would have been higher than actual emissions. This holds for both the monetary and the physical DTA, however, the difference between the EWoT and the actual emissions is notably higher for the 'physical DTA'. For the year 2007, the NEA in Spain reached to $37 \mathrm{MtCO}_{2} \mathrm{e}$ according to the 'monetary DTA', whereas the 'physical DTA' estimates that additional 124 $\mathrm{MtCO}_{2} \mathrm{e}$ would have been generated in Spain without trade. Furthermore, for the whole period, the cumulative NEA estimated by applying the 'physical DTA' is around 3 times higher than the resulting from the 'monetary DTA'.

Table 2

These discrepancies between the results derived from the 'monetary DTA' and the 'physical DTA' are due to the asymmetries between the prices of domestic produced and imported goods. In order to further investigate this issue we have carried an

11 For the imports of services, the usual 'monetary DTA' has also been applied together with the 'physical DTA'. As a consequence, the differences between the monetary and the physical DTA are completely determined by the deflation of the imports of primary and industrial commodities only. 
exercise of comparative statics to assess the effects of the difference in the prices of each of the 35 commodities for which we have applied the 'physical DTA'.12

Table 3 offers a summary of the results of this analysis for 2007. The first two columns of Table 3 show the goods for which the 'physical DTA' estimates more EWoT than the 'monetary DTA'. For this group of commodities the difference between the 'physical DTA' and the 'monetary DTA' reaches nearly $90 \mathrm{MtCO}_{2} \mathrm{e}$. Within this group the higher differences are found in 'wearing apparel' (17 $\left.\mathrm{MtCO}_{2} \mathrm{e}\right)$, 'basic metals' (15 $\left.\mathrm{MtCO}_{2} \mathrm{e}\right)$, 'electronic equipment' (15 $\left.\mathrm{MtCO}_{2} \mathrm{e}\right)$, 'agriculture' (12 $\left.\mathrm{MtCO}_{2} \mathrm{e}\right)$, and 'leather and leather products' (8,5 $\left.\mathrm{MtCO}_{2} \mathrm{e}\right)$. These five commodities account for more than $75 \%$ of the total difference between the physical and the monetary approach.

Likewise, columns 3rd and 4th show the figures for those commodities for which the 'physical DTA' reports less emissions than the 'monetary DTA'. According to our estimations, for these goods the total difference between the EWoT estimated with the 'physical DTA' and the 'monetary DTA' is $13 \mathrm{MtCO}_{2} \mathrm{e}$. The five commodities showing the largest differences account for $70 \%$ of the total ('chemicals' $3.7 \mathrm{MtCO}_{2} \mathrm{e}$, 'motor vehicles' 1.6 $\mathrm{MtCO}_{2} \mathrm{e}$, 'machinery and equipment' $1.5 \mathrm{MtCO}_{2} \mathrm{e}$, 'other transport equipment' 1.5 $\mathrm{MtCO}_{2} \mathrm{e}$, and 'medical, precision and optical instruments' 0.8 $\mathrm{MtCO}_{2} \mathrm{e}$ ).

\section{Table 3}

We can further investigate these differences by assessing the detailed information on the trade flows provided by trade statistics. We concentrate our attention in some of the goods with the largest differences between physical and monetary approaches in 2007.

In the case of 'wearing apparel', for which we found the largest positive difference Spain exported to the rest of the world 4 billion $€$ with an average price of 61 $€ / \mathrm{kg}$ and imported from the rest of the world 8.4 billion $€$ with an average price of 14 $€ / \mathrm{kg}$. Thus, export prices by mass unity are 4.34 times higher than import prices (see the

12 The effect of each deflator is calculated by comparing the EWoT resulting from the 'monetary DTA' and the emissions from a 'physical DTA' in which all the elements of the vector of deflators, except the corresponding to the deflator that we are analyzing, have been replaced by 1 .We have applied this method for each of the 35 deflators separately, as a consequence, if we aggregate the individual results and compare them with the total difference between the physical and the monetary DTA, we observe a discrepancy due to the cross effects of the deflators. 
deflator in Table 2). Moreover, for 206 of the 219 'wearing product' types reported by trade statistics at TARIC 6-digit classification, export prices by physical unit were higher than import prices. If we look at the figures aggregated at 4 digit, we find that 53\% of the imports of textiles are concentrated in 4 categories namely: 6109 'T-shirts, singlets and other vests, knitted or crocheted', 6110 'jerseys, pullovers, cardigans, waistcoats and similar articles, knitted or crocheted', 6003 'knitted or crocheted fabrics of a width not exceeding $30 \mathrm{~cm}$, other than those of heading 6001 or 6002', and 6004 'knitted or crocheted fabrics of a width exceeding $30 \mathrm{~cm}$, containing by weight $5 \%$ or more of elastomeric yarn or rubber thread, other than those of heading 6001'. For these categories the prices of imports exceed that of exports by 3.7, 4.3, 5.3 and 5.2 times respectively. Thus, the differences in prices remain even when we disaggregate the sector in much more specific subsectors.

For many sectors it is clear that the origin of the dramatic difference in the average price is double: different prices for the same type of product but also -and perhaps mainly- differences in the composition of imported and exported commodities. As we explained in the previous section, the physical approach is better than the monetary to avoid price bias. As we also pointed out before, the differences in the composition of commodities have not a simple solution, but in this case we can conjecture that physical approach is probably better than monetary. We can see the double origin of differences for instance in basic metals, agricultural products, and pulp, paper and paper products.

In the case of 'basic metals', in 2007 Spain exported 13.3 billion $€$ of 'basic metals' and imported 20.1 billion $€$, being the average price of exports 1.75 times higher than that of imports $(1.33 € / \mathrm{kg}$ versus $0.76 € / \mathrm{kg})$. Almost $20 \%$ of those imports corresponded to category 2704 'ferrous waste and scrap; remelting scrap ingots of iron or steel' for which the price of exports was 2.4 times higher than the price of imports. This category covers 7 different types of ferrous scrap and for all of them the price of exports was higher than that of exports. Moreover, Spanish exports of scrap, which have a lower price in relation to other categories, account only for $2 \%$ of the exports of 'basic metals', while the share of high-priced processed goods in exports is higher than in imports. This commodity asymmetry in the composition of imports and exports also contributes to widen the gap between the prices of traded goods. 
The case of agricultural products is also very clarifying. In the year 2007 Spain exported 9.4 billion $€$ of agricultural products and imported almost 7.3 billion $€$, with an average price of $0.78 € / \mathrm{kg}$ and $0.37 € / \mathrm{kg}$ respectively. Within the imports of agricultural products, cereals accounted for two thirds of total imports. For all the crops included in cereals category, the average price of exports was higher than the price of imports: $+28 \%$ for wheat, $+7 \%$ for rye, $+33 \%$ for barley', $+3 \%$ for oats, $71 \%$ for maize (corn), $+32 \%$ for rice, $+58 \%$ for grain sorghum, and $+24 \%$ for buckwheat, millet, canary seed and other cereals. On the other hand, cereals account for only 5\% of Spanish exports of agricultural products, and the price of these commodities is lower than the price of the main categories of agricultural exports.

In the case of 'pulp, paper and paper products', Spain exported 3.7 billion $€$ and imported 4.6 billion $€$, being the average price of exports 1.2 times higher than that of imports $(1.05 € / \mathrm{kg}$ versus $0.89 € / \mathrm{kg})$. We observe that the shares of 'pulp' and 'paper' in the composition of imports were $78 \%$ and $22 \%$ respectively, while in the case of exports they were $72 \%$ and $28 \%$. On the other hand, the price of 'paper' is 2 times the price of 'pulp', and the price of the exports of 'pulp' exceeds the price of imports by a factor of 1.16 .

On the other hand, as pointed above, for some products the prices of exports are lower than those of imports and, therefore, the 'monetary DTA' would probably be overestimating the EWoT. That would be the case of 'motor vehicles': in 2007 Spain exported 40.4 billion $€$ of these products at an average price of $12.7 € / \mathrm{kg}$ and imported 45 billion $€$ at $13.7 € / \mathrm{kg}$.

\section{Conclusions}

The estimation of the emission avoided allows assessing to what extent countries are taking advantage from trade by "displacing" pollution to other regions. This question is connected to some relevant policy issues such as the 'environmental load displacement', the 'Environmental Kuznets Curve', the 'pollution haven hypothesis' or the 'carbon leakage'.

The proper way to estimate emissions avoided by trade is to apply EE-IO models using the DTA. We have shown that the results are very influenced by the method used for the quantification of imports. The standard method is based on the calculation of the 
emissions generated to produce domestically a monetary value of products equivalent to the monetary value of the imports ('monetary DTA'). However, price differences between domestic and imported goods and aggregation can result in biased estimations. With the aim of overcome the first of these limitations, we have developed an innovative approach for calculating the emissions avoided by trade. This approach is based on the idea that the emissions avoided by imports should reflect the pollution to produce domestically the same quantity of imported goods measured in physical terms ('physical DTA').

We have applied both methodologies to the analysis of GHG emissions avoided by trade in Spain 1995-2007. Both methodologies show that Spain is taking advantage from trade, in the sense that in absence of trade Spanish emissions would have been higher than actual emissions. However, for the whole period, the net emissions avoided by trade resulting from the 'physical DTA' are 3 times higher than the ones from the 'monetary DTA' and they increase more. As a consequence, the 'monetary DTA' would be underestimating the emissions avoided by trade.

We have shown that, from a theoretical view point, a 'physical DTA', focused on the pollution to domestically produce the imports measured in physical units, would be a better approach. The 'physical DTA' calculates embodied emissions in imports according to real quantities traded, leaving out of the analysis the effect of different prices; on the contrary, the 'monetary DTA' is biased by price differences. Therefore, in general, when applying the DTA to the estimation of the emissions avoided by trade, we consider that the estimations can be improved by substituting -whenever possiblemonetary by physical trade data. Moreover, this conclusion can be extended to those cases in which the DTA is also used to calculate carbon footprints or ETB.

\section{References}

Ackerman, F., Ishikawa, M., Suga, M., 2007. The carbon content of Japan-US trade. Energy Policy, 35(9), 4455-4462.

Agencia Tributaria, 2010. Estadísticas Comercio Exterior [Foreign Trade Statistic]. http://www.aeat.es/ Last access November 2010. 
Arrow, K., Bolin, B., Costanza, R., Dasgupta, P., Folke, C., Holling, C. S., Jansson, B. O., Levin, S., Mäler, K. G., Perrings, C., and Pimentel, D. 1995. Economic growth, carrying capacity and the environment. Science, 268(5210), 520-521.

Arto. I., 2009. Emisiones de gases de efecto invernadero, comercio internacional y hábitos de consumo en España, Papeles de Economía Española 121, 100-111.

Arto, I., Roca, J., Serrano, M., 2010a. Accounting for embodied emissions in international trade: physical vs monetary trade flows. Summer School on Environmental accounting: externality valuation and Input-Output tools for policy analysis, 11 - 17 July 2010, Venice, Italy.

Arto, I., Roca, J., Serrano, M., 2010b. The countries' responsibility for greenhouse emissions: the role of trade. An application to Spain. International Society for Ecological Economics, 2010 Conference, 22 - 25 August 2010, Oldenburg \& Bremen, Germany.

Arto, I., Roca, J., Serrano, M., 2012. Emisiones territoriales y fuga de emisiones. Análisis del caso español. Revista Iberoamericana de Economía Ecológica, 18, 73-87.

Dietzenbacher, E., Mukhopadhyay, K., 2007. An empirical examination of the pollution haven hypothesis for India: Towards a green Leontief paradox? Environmental and Resource Economics, 36(4), 427-449.

Dietzenbacher, E., Tukker, A., (eds.) 2013. Global multiregional Input-Output frameworks, Special Issue, Economic Systems Research, 25(1), 1-156.

Eurostat, 2008. Eurostat Manual of Supply, Use and input-Output Tables. Office for Official Publications of the European Communities, Luxembourg.

Gallego, B., Lenzen, M., 2005. A consistent input-output formulation of shared consumer and producer responsibility. Economic Systems Research 17 (4), 365-391.

Grossman, G.M., Krueger, A.B., 1991. Environmental impacts of North American Free Trade Agreement. NBER Working Paper 3914. National Bureau of Economic Research (NBER), Cambridge, Massachusetts.

INE, 2010a. Spanish National Accounts. Base 2000 / Input-output Framework. 20002007. Madrid: Instituto Nacional de Estadística. http://www.ine.es Last access November 2010. 
INE, 2010b. Spanish National Accounts. Base 1995 / Input-output Framework. 19951999. Madrid: Instituto Nacional de Estadística. http://www.ine.es Last access November 2010.

INE, 2010c. Atmospheric emissions satellite accounts. Base 2010. 1995-2007. Madrid: Instituto Nacional de Estadística. http://www.ine.es Last access November 2010.

Lenzen, M., Murray, J., Sack, F., and Wiedmann, T., 2007. Shared producer and consumer responsibility - Theory and practice, Ecological Economics, 61(1), 27-42.

Levinson, A., 2009. Technology, international trade, and pollution from US manufacturing. The American Economic Review, 99(5), 2177-2192.

Lin, B., Sun, S., 2010. Evaluating carbon dioxide emissions in international trade of China. Energy Policy, 38(1), 613-621.

Liu, X., Ishikawa, M., Wang, C., Dong, Y., Liu, W., 2010. Analyses of CO2 emissions embodied in Japan-China trade. Energy Policy, 38(3), 1510-1518.

Marin, G., Mazzanti, M., Montini, A., 2012. Linking NAMEA and Input output for 'consumption vs. production perspective' analyses: Evidence on emission efficiency and aggregation biases using the Italian and Spanish environmental accounts. Ecological Economics 74, 71-84.

Mattoo, A., Subramanian, A., van der Mensbrugghe, D., He, J., 2009. Reconciling climate change and trade policy. Working Paper 189, November 2009, Center for Global Development.

Muradian, R., Martínez-Alier, J., 2001. Trade and the environment: from a 'Southern' perspective. Ecological Economics 36(2), 281-297.

Peters, G., 2008. From production-based to consumption-based national emission inventories. Ecological Economics 65(1), 13-23.

Peters, G., Hertwich, E.G., 2008. CO2 embodied in international trade with implications for global climate policy. Environmental Science and Technology 42(5), 1401-1407.

Peters, G.P., Weber, C.L., Guan, D., Hubacek, K., 2007. China's growing $\mathrm{CO}_{2}$ emissions-A race between increasing consumption and efficiency gains. Environmental Science and Technology, 41(17), 5939-5944. 
Peters, G.P., Minx, J., Weber, C.L., Edenhofer, O., 2011. Growth in emission transfers via international trade from 1990 to 2008. Proceedings of the National Academy of Sciences 108 (21), 8903-8908.

Roca, J., 2003. Do individual preferences explain the environmental Kuznets curve?, Ecological Economics 45(1), 3-10.

Rueda-Cantuche, José M., 2011. Comparisons of the European carbon footprint (20002006) from three different perspectives within a multiregional framework, in: Costantini, V., Mazzanti, M. and Montini, A. (Eds.), Hybrid Economic-Environmental Accounts, 125-139. Routledge, New York.

Serrano, M., Dietzenbacher, E., 2010. Responsibility and trade emission balances: An evaluation of approaches, Ecological Economics 69(11), 2224-2232.

Stahmer, C., 2000. The magic triangle of Input-Output tables, in Simon, S. and Proops, J.L.R. (Eds.), Greening the Accounts (Current Issues in Ecological Economics). Edward Elgar, Cheltenham, UK, 123-154.

Stern, D.I., Common, M.S., Barbier, E.B., 1996. Economic growth and environmental degradation: the environmental Kuznets curve and sustainable development. World Development 24(7), 1151-1160.

Strassert, G., 2002. Physical input-output accounting, in Ayres, R.U. and Ayres, L.W. (Eds.), A Handbook of Industrial Ecology. Edward Elgar, UK.

Tukker, A., de Koning, A., Wood, R., Moll, S., Bouwmeester, M.C., 2013. Price corrected Domestic Technology Assumption - A method to assess pollution embodied in trade using primary official statistics only. With a case on $\mathrm{CO}_{2}$ emissions embodied in imports to Europe. Environmental Science and Technology, 47(4), 1775-1783.

Wiedmann, T., 2009. A review of recent multi-region input-output models used for consumption-based emission and resource accounting, Ecological Economics, 69(2), 221-222.

Wiedmann, T., Lenzen, M., Turner, K., Barrett, J., 2007. Examining the global environmental impact of regional consumption activities - Part 2: Review of inputoutput models for the assessment of environmental impacts embodied in trade. Ecological Economics 65(1), 15-26. 
Weidema, B., Suh, S., Notten, P., 2006. Setting priorities within product-oriented environmental policy, the Danish perspectives. Journal of Industrial Ecology 10(3), 7387.

Wood, R., Dey, C.J., 2009. Australia's carbon footprint. Economic Systems Research 21(3), 243-266.

Wyckoff A.W., Roop J.M., 1994. The embodiment of carbon in imports of manufactured products: implications for international agreements on greenhouse gas emissions. Energy Policy 22(3), 187-194.

Zhang, Y., 2012. Scale, technique and composition effects in trade-related carbon emissions in China. Environmental and Resource Economics, 51(3), 371-389. 
Figure 1: Input-Output table

\begin{tabular}{|c|c|c|c|c|}
\hline & \multirow{2}{*}{ Intermediate use } & \multicolumn{2}{|c|}{ Final uses } & \multirow{2}{*}{$\begin{array}{l}\text { Total } \\
\text { output }\end{array}$} \\
\hline & & Domestic & Exports & \\
\hline Domestic & $\mathbf{Z}^{\mathrm{D}}$ & $f^{D}$ & e & $\mathbf{x}$ \\
\hline Imports & $\mathrm{Z}^{\mathrm{M}}$ & $f^{M}$ & 0 & $x^{M}$ \\
\hline Value added & $w^{\prime}$ & & & \\
\hline Total inputs & $\mathbf{x}^{\prime}$ & & & \\
\hline Emissions & $g^{\prime}$ & & & \\
\hline
\end{tabular}


Figure 2: Actual emissions and emissions without trade: monetary and physical DTA. Spain, 1995 2007 (Index $1995=100$ )

Error! No és un enllaç vàlid.

Source: own elaboration based on INE (2010a,b,c) and Agencia Tributaria (2010). 
Table 1: Deflator of imported goods for applying the 'physical DTA'. Spain, 1995-2007

\begin{tabular}{|c|c|c|c|c|c|c|c|c|c|c|c|c|c|}
\hline & 1995 & 1996 & 1997 & 1998 & 1999 & 2000 & 2001 & 2002 & 2003 & 2004 & 2005 & 2006 & 2007 \\
\hline Agriculture & 2.19 & 1.86 & 1.86 & 1.99 & 2.10 & 2.16 & 2.28 & 2.62 & 2.45 & 2.33 & 3.03 & 2.52 & 2.10 \\
\hline Forestry & 1.39 & 2.34 & 1.37 & 1.32 & 1.56 & 2.20 & 2.47 & 3.92 & 3.58 & 3.17 & 4.08 & 0.50 & 0.42 \\
\hline Fishing & 0.64 & 0.77 & 0.86 & 0.89 & 1.04 & 1.11 & 1.00 & 1.01 & 0.97 & 0.95 & 0.82 & 0.75 & 0.74 \\
\hline Coal and lignite & 3.20 & 4.12 & 2.95 & 3.36 & 4.11 & 3.28 & 2.56 & 2.44 & 2.21 & 2.00 & 2.06 & 1.83 & 1.01 \\
\hline Metal ores & 0.56 & 0.59 & 1.78 & 1.88 & 2.35 & 2.29 & 1.96 & 10.24 & 4.94 & 8.25 & 3.38 & 4.36 & 4.16 \\
\hline \multirow{2}{*}{$\begin{array}{l}\text { Other mining } \\
\text { Coke and refined } \\
\text { petroleum }\end{array}$} & 0.49 & 0.57 & 0.61 & 0.56 & 0.83 & 0.66 & 0.73 & 0.82 & 0.86 & 0.88 & 0.85 & 0.69 & 0.78 \\
\hline & 1.01 & 1.00 & 1.00 & 0.93 & 1.06 & 1.09 & 1.08 & 1.16 & 1.06 & 1.03 & 1.08 & 1.06 & 1.10 \\
\hline Meat products & 1.01 & 1.13 & 1.05 & 1.00 & 0.95 & 1.01 & 0.99 & 0.89 & 0.86 & 0.83 & 0.84 & 0.80 & 0.77 \\
\hline Dairy products & 1.37 & 1.23 & 1.33 & 1.26 & 1.09 & 1.14 & 1.05 & 1.07 & 1.00 & 1.09 & 1.19 & 1.20 & 1.25 \\
\hline Other food products & 1.49 & 1.39 & 1.36 & 1.38 & 1.50 & 1.41 & 1.30 & 1.46 & 1.33 & 1.39 & 1.53 & 1.55 & 1.47 \\
\hline Beverages & 0.90 & 0.77 & 0.66 & 0.71 & 1.19 & 1.17 & 1.25 & 3.39 & 1.18 & 1.24 & 1.31 & 0.48 & 0.64 \\
\hline Tobacco products & 0.23 & 0.46 & 0.57 & 0.53 & 0.49 & 0.51 & 0.39 & 0.39 & 0.32 & 0.37 & 0.34 & 0.12 & 0.09 \\
\hline Textiles & 1.43 & 1.25 & 1.24 & 1.27 & 1.29 & 1.18 & 1.26 & 1.27 & 1.31 & 1.30 & 1.15 & 1.44 & 1.58 \\
\hline \multirow{5}{*}{$\begin{array}{l}\text { Wearing apparel } \\
\text { Leather and leath } \\
\text { products } \\
\text { Wood and wood } \\
\text { products } \\
\text { Pulp, paper and } \\
\text { paper products } \\
\text { Publishing and } \\
\text { printing }\end{array}$} & 1.78 & 2.01 & 1.64 & 1.78 & 2.20 & 1.99 & 1.84 & 1.78 & 1.94 & 2.34 & 2.16 & 4.49 & 4.34 \\
\hline & 2.47 & 2.32 & 2.18 & 2.20 & 4.62 & 3.86 & 4.06 & 4.36 & 4.45 & 4.05 & 3.93 & 4.17 & 4.26 \\
\hline & 1.58 & 1.59 & 1.61 & 1.89 & 1.84 & 1.69 & 1.55 & 1.41 & 1.54 & 1.54 & 1.44 & 1.39 & 1.51 \\
\hline & 1.18 & 1.10 & 1.18 & 1.21 & 1.16 & 1.26 & 1.16 & 1.24 & 1.20 & 1.14 & 1.09 & 1.30 & 1.28 \\
\hline & 0.52 & 0.46 & 0.51 & 0.49 & 0.57 & 0.50 & 0.45 & 0.41 & 0.39 & 0.37 & 0.44 & 0.45 & 0.42 \\
\hline \multirow{4}{*}{$\begin{array}{l}\text { Chemicals } \\
\text { Rubber and plastic } \\
\text { products } \\
\text { Cement, lime and } \\
\text { plaster } \\
\text { Glass and glass } \\
\text { products }\end{array}$} & 0.68 & 0.64 & 0.76 & 0.83 & 0.80 & 0.88 & 0.86 & 0.88 & 0.82 & 0.79 & 0.81 & 0.82 & 0.85 \\
\hline & 1.03 & 0.97 & 0.96 & 0.98 & 1.04 & 0.90 & 0.88 & 0.94 & 0.96 & 0.93 & 0.90 & 1.12 & 0.98 \\
\hline & 0.76 & 0.77 & 0.81 & 0.92 & 1.12 & 1.13 & 1.31 & 1.41 & 1.60 & 1.46 & 1.48 & 1.67 & 1.65 \\
\hline & 1.27 & 1.79 & 1.35 & 1.33 & 1.33 & 1.23 & 1.21 & 1.16 & 1.32 & 1.20 & 1.38 & 1.41 & 1.40 \\
\hline \multirow{2}{*}{$\begin{array}{l}\text { Ceramic goods } \\
\text { Other non-metallic } \\
\text { mineral products }\end{array}$} & 0.45 & 0.42 & 0.37 & 0.38 & 0.44 & 0.39 & 0.35 & 0.35 & 0.39 & 0.40 & 0.41 & 0.54 & 0.75 \\
\hline & 0.52 & 0.54 & 0.49 & 0.54 & 0.59 & 0.50 & 0.47 & 0.63 & 0.59 & 0.63 & 0.72 & 0.70 & 0.83 \\
\hline Basic $n$ & 1.55 & 1.26 & 1.74 & 1.75 & 1.90 & 1.73 & 1.77 & 1.70 & 1.66 & 1.59 & 1.65 & 1.87 & 1.75 \\
\hline \multirow{3}{*}{$\begin{array}{l}\text { Metal products } \\
\text { Machinery and } \\
\text { equipment } \\
\text { Machinery and } \\
\text { equipment }\end{array}$} & 0.86 & 0.86 & 1.21 & 0.79 & 0.94 & 0.75 & 0.85 & 0.95 & 0.98 & 0.96 & 1.02 & 1.01 & 0.97 \\
\hline & 0.79 & 0.81 & 0.89 & 1.17 & 0.88 & 0.85 & 0.83 & 0.92 & 0.84 & 0.85 & 0.77 & 0.87 & 0.86 \\
\hline & 1.13 & 1.07 & 0.92 & 0.98 & 2.12 & 1.40 & 1.06 & 1.56 & 1.25 & 1.51 & 1.39 & 0.89 & 0.80 \\
\hline Electrical & 0.70 & 0.70 & 0.66 & 0.97 & 0.77 & 0.78 & 0.76 & 0.72 & 0.75 & 0.77 & 0.72 & 0.85 & 0.92 \\
\hline \multirow{2}{*}{$\begin{array}{l}\text { Electronic equipment } \\
\text { Precision and optical } \\
\text { instruments }\end{array}$} & 0.95 & 0.83 & 0.93 & 0.75 & 0.36 & 0.47 & 0.62 & 0.72 & 0.86 & 0.92 & 0.58 & 1.93 & 1.82 \\
\hline & 0.72 & 0.72 & 0.71 & 0.92 & 1.90 & 0.70 & 0.68 & 0.76 & 0.71 & 0.71 & 0.68 & 0.22 & 0.65 \\
\hline \multirow{3}{*}{$\begin{array}{l}\text { Motor vehicles } \\
\text { Other transport } \\
\text { equipment } \\
\text { Furniture and other } \\
\text { manufactures }\end{array}$} & 0.85 & 0.89 & 0.92 & 0.91 & 0.86 & 0.88 & 0.90 & 0.87 & 0.83 & 0.82 & 0.81 & 0.98 & 0.93 \\
\hline & 0.55 & 0.38 & 0.72 & 0.93 & 0.25 & 0.44 & 1.62 & 1.03 & 0.86 & 0.87 & 1.10 & 0.91 & 0.19 \\
\hline & 0.88 & 0.82 & 0.74 & 0.33 & 0.84 & 1.00 & 0.87 & 0.99 & 1.02 & 1.13 & 1.15 & 1.18 & 1.14 \\
\hline
\end{tabular}

Source: own elaboration based on INE (2010a,b,c) and Agencia Tributaria (2010).

Note: DTA: Domestic technology assumption. 
Table 2: Actual emissions, emissions without trade and net avoided emissions: monetary and physical DTA. Spain, 1995-2007 (MtCO2e)

\begin{tabular}{|c|c|c|c|c|c|c|c|c|}
\hline & \multirow[b]{3}{*}{$\begin{array}{l}\text { Actual } \\
\text { emissions }\end{array}$} & \multicolumn{2}{|c|}{ Monetary DTA } & \multicolumn{2}{|c|}{ Physical DTA } & \multicolumn{3}{|c|}{$\begin{array}{c}\text { Difference between } \\
\text { physical and monetary DTA }\end{array}$} \\
\hline & & EWoT & NEA & EWoT & NEA & & & NEA \\
\hline & & $\mathrm{MtCO}_{2} \mathrm{e}$ & $\mathrm{MtCO}_{2} \mathrm{e}$ & $\mathrm{MtCO}_{2} \mathrm{e}$ & $\mathrm{MtCO}_{2} \mathrm{e}$ & $\mathrm{MtCO}_{2} \mathrm{e}$ & $\%$ & $\%$ \\
\hline 1995 & 312 & 322 & 10 & 337 & 24 & 14 & $4.5 \%$ & $143.2 \%$ \\
\hline 1996 & 304 & 309 & 6 & 316 & 13 & 7 & $2.3 \%$ & $125.7 \%$ \\
\hline 1997 & 325 & 329 & 4 & 343 & 17 & 14 & $4.2 \%$ & $370.3 \%$ \\
\hline 1998 & 335 & 345 & 10 & 366 & 31 & 21 & $6.2 \%$ & $221.6 \%$ \\
\hline 1999 & 363 & 377 & 14 & 410 & 47 & 33 & $8.8 \%$ & $233.7 \%$ \\
\hline 2000 & 377 & 396 & 20 & 424 & 47 & 28 & $7.0 \%$ & $141.3 \%$ \\
\hline 2001 & 377 & 395 & 18 & 421 & 44 & 26 & $6.6 \%$ & $142.8 \%$ \\
\hline 2002 & 394 & 411 & 17 & 460 & 66 & 49 & $11.9 \%$ & $283.2 \%$ \\
\hline 2003 & 400 & 418 & 18 & 448 & 48 & 30 & $7.2 \%$ & $168.6 \%$ \\
\hline 2004 & 416 & 442 & 25 & 478 & 61 & 36 & $8.2 \%$ & $143.6 \%$ \\
\hline 2005 & 432 & 464 & 32 & 509 & 77 & 45 & $9.7 \%$ & $142.7 \%$ \\
\hline 2006 & 425 & 458 & 33 & 549 & 124 & 91 & $19.8 \%$ & $274.4 \%$ \\
\hline 2007 & 435 & 472 & 37 & 560 & 124 & 88 & $18.6 \%$ & $238.4 \%$ \\
\hline $\begin{array}{l}\text { Cumulative } \\
1995 \text { to } 2007\end{array}$ & 4,896 & 5,139 & 242 & 5,620 & 724 & 482 & $9.4 \%$ & $198.6 \%$ \\
\hline
\end{tabular}

Source: own elaboration based on INE (2010a,b,c) and Agencia Tributaria (2010).

Note 1: DTA: Domestic Technology Assumption; EWoT: Emissions Without Trade; NEA: Net Emissions Avoided by trade; $\mathrm{Mt}=106$ tonnes.

Note 2: DTA: Actual emissions and EWoT include sectoral emissions and direct emissions from households. 
Table 3: Effects of the price differences by commodity in the estimation of the emissions without trade according to the 'physical DTA' with respect to the 'monetary DTA'. Spain, 2007 (ktCO2e)

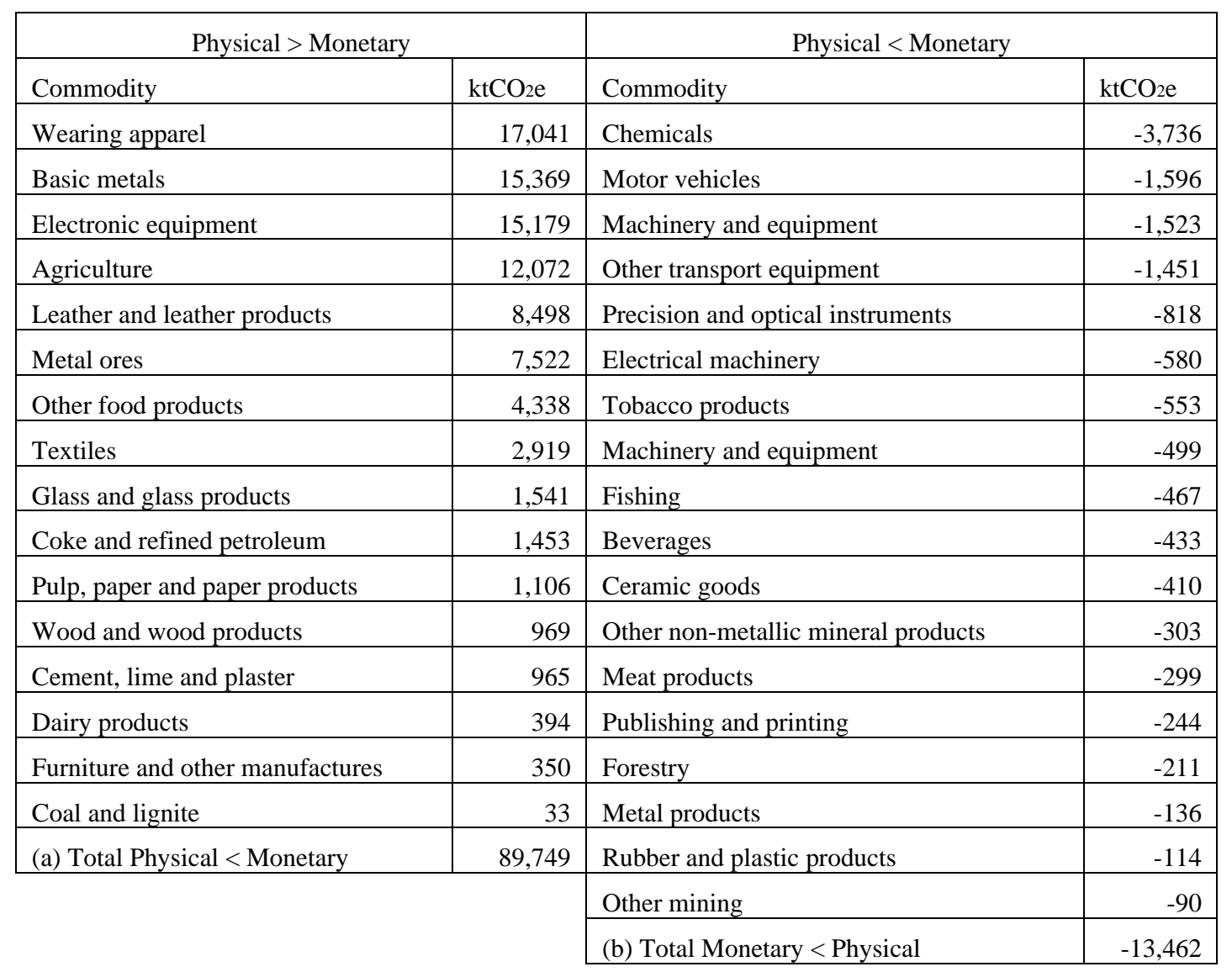

\begin{tabular}{|l|r|}
\hline (c) Cross effects & 11,315 \\
\hline
\end{tabular}

\begin{tabular}{|l|r|}
\hline Total (a)+(b)+(c) & 87,602 \\
\hline
\end{tabular}

Source: own elaboration.

Note 1: DTA: Domestic Technology Assumption; kt = 103 tonnes.

Note 2: Cross effects refer to the joint effects of changing more than one price at the same time. 